\title{
Online Shopping System Research
}

\author{
Bingji Li \\ Weifang University of Science and Technology, ShanDong ShouGuang, 262700,China.
}

Keywords: Online shopping; The ASP; Design; Test

\begin{abstract}
This article first introduced the development background and present situation of the online shopping system, then discusses the system design objectives, system requirements and overall design .This paper discusses the design and implementation of the system in detail. Finally, the online shopping system is detected.
\end{abstract}

\section{Introduction}

Get the rapid development of the Internet in recent years, the Internet has gradually become the best channel to provide information collection, began to join the ranks of these traditional areas. E-commerce in the new electronic age began to a wide range of popular. More and more companies or businessmen began to initiate a shop on the Internet, with the display of a new shopping concept to consumers.

\section{An overview of the online shopping system}

The purpose and significance of the system. Information technology, database technology and Internet technology in the new era of development, the network process is in constant speed, this this background, the traditional shopping way also gradually cannot meet the demand of the fast pace of life, the advantages of the Internet by corporate IT department to realize gradually, electronic commerce is in such a complex background. As the electronic commerce technology unceasingly mature and perfect, e-commerce is becoming more and more powerful function to exert advantages, registered users never leave home, you can search on the Internet buying all kinds of goods to their need, preliminary to let people feel the time is convenient to shopping pleasure. This graduation design is the creation of such an e-commerce system - the online shopping system.

Basic structure of the system. This system mainly contains the by products, customers, orders, custom, purchase, report forms management subsystem, the user management subsystem module products such as pay, order management subsystem and management subsystem and management subsystem, and statistics.

Basic function of the system. 1)Login and registration features: users can register, after membership to browse and purchase of goods.

2)Commodity search function: users can enter key and fuzzy words to find their favorite products.

3)User information function: users can fill in their own account information, the contents of the contents according to the user's own settings to set the confidentiality.

4)The Shopping Cart feature: the user can choose the goods into the shopping cart, the choice of whether to submit the purchase.

5)Message board function: users can leave a message in the message area exchange, can also give the site administrator a message. The website administrator received a message, will respond.

6)Purchase orders and purchase function: After the submission of the order, the receipt of the goods, payment, that is, the purchase process to complete. 
7)Backstage function: the website administrator will carry on a series of background management operations to the commodity import, export, the commodity display and according to the user submit purchase information.

First each user in the design of online shopping system after registration, you can browse the website of all kinds of commodities in online, next to each kind of commodity will text and image links, users only need to click "subscribe", and can carry out the order, goods orders will be placed in the shopping cart, shopping cart is submitted, the pop-up dialog box, asking the user to confirm. Users can also leave a message on the message board. the user after the submission of the order information and customer contact information will be stored in the database, waiting for the site administrator query. Product orders will be the site administrator statistics, the user can sign in with the password of the account, $\log$ in to view the history and current order operation information.

\section{Online shopping system development environment and tools}

Configuration requirements of system environment. Operating system: Windows 2000 or Windows XP Professional.

CPU: The request is not high, only can smooth running Windows series of operating systems. ASP code efficiency increased along with the to speed up the processing speed of the CPU.

Memory: Windows XP recommends the use of more than $128 \mathrm{MB}$ of memories.

Hard disk space: $10 \mathrm{~g}$.

Dreamweaver development tools. Dreamweaver is a professional HTML editor for Web pages, Web sites, Web applications and design, code, and development. We can write HTML code directly, can also work in the visual editing environment experience, either way, Dreamweaver will provide us with the tool that helps a lot. We enjoy the wonderful experience of Web creation.

ASP technology. ASP (Active Server Pages) located in essence is a server-side script running environment. In this environment, as long as the client executable using HTML code browser, you can browse through ASP designed page content. The user can accord to own need to create and run dynamic interactive Web server applications, such as interactive dynamic Web pages, including the use of the HTML form to collect and process information, download and upload, etc.

The database. Data is loaded or record information according to certain rules of permutation and combination of physical signs. Can be Numbers, text, images, also can be a computer code.

ACSEE database. Access is a kind of relation database, it is an object-oriented development tools, various functions of the database system by object-oriented objectification, and encapsulated in all kinds of objects with the functions of database management. It assumes that an application system is composed of a series of object, it defines a set of methods and properties for each object, and the behavior and characteristics of the object are defined, the user can also according to the need to give the object extension methods and properties. By the method of the object, attribute database operation and management, the development of the user work greatly simplified. At the same time, the way of object-oriented development and making the development application more convenient. Access database in the form of file save. The file extension is the MDB.

SQL statement. SQL is industry standard database manipulation language, used for data access and query, update and manage a relational database system, also is a database script file extension, and a relational database management system can be the language to manipulate. Because SQL is between visual basic and the jet database engine and running on the Windows NT server database engine to communicate with the basic method, so its importance for Visual Basic programmers was of major importance. 


\section{The design of the online shopping system}

The principle of the system. Now popular online shopping system should not have a beautiful page, more rigorous planning. It is vitally important to every tiny link. In this way can we make in the automated trading avoid unnecessary mistakes happen. We will use Dreamweaver to edit web pages, HTML, ASP technology, and using ASP technology to the database associated with dynamic web pages. The development of this system is based on the e-commerce application of the most popular B/S (Browser/Server) is the Browser/Server structure. The principle is shown in Fig. 1.

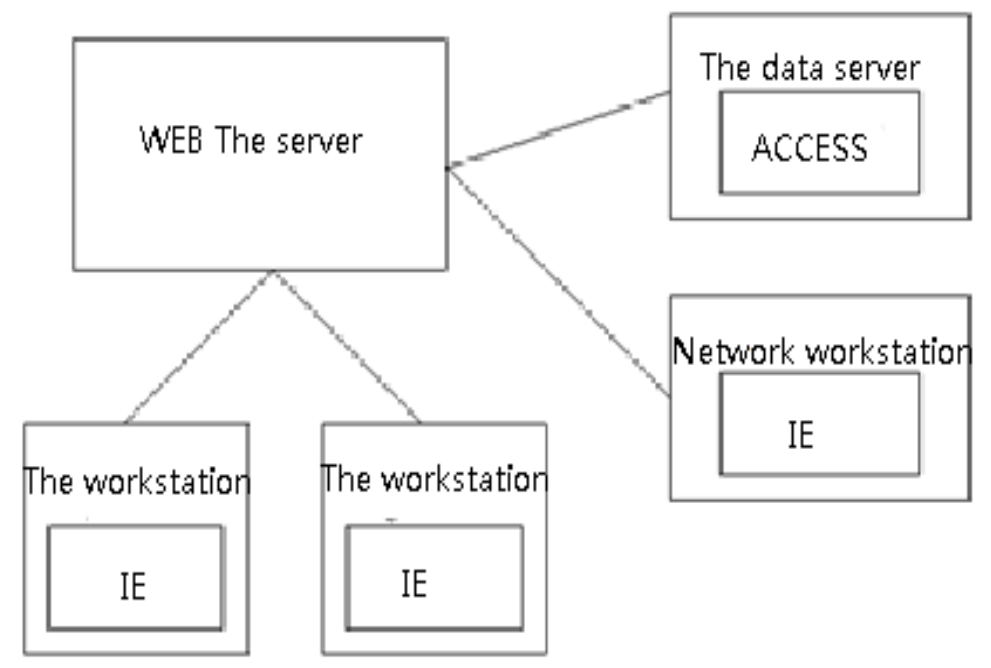

Fig. 1 Server structure

The main system structure of online commodity system includes: data server, WEB server, background management platform, client.

Application system design mainly considers the business and technical factors include: business processing mode, the amount of data processing, data storage, application design, server design, store design, safety design.

The data flow of the system. According to the above chapters, we expected to have in the whole shopping system features are an integral part of the understanding, we will establish a user register, login function, can be released commodity information, query, for their goods with a shopping cart, realize the order goods, be able to leave a message, to the background administrator operation functions such as shopping system.

So, we design the module mainly divided into the following several parts: a. register/login module; B. the commodity classification module; C. commodity search module; D. shopping cart module; E. message board module; F. order query module; G. the order management module. The main module and data flow diagram is as follows: 


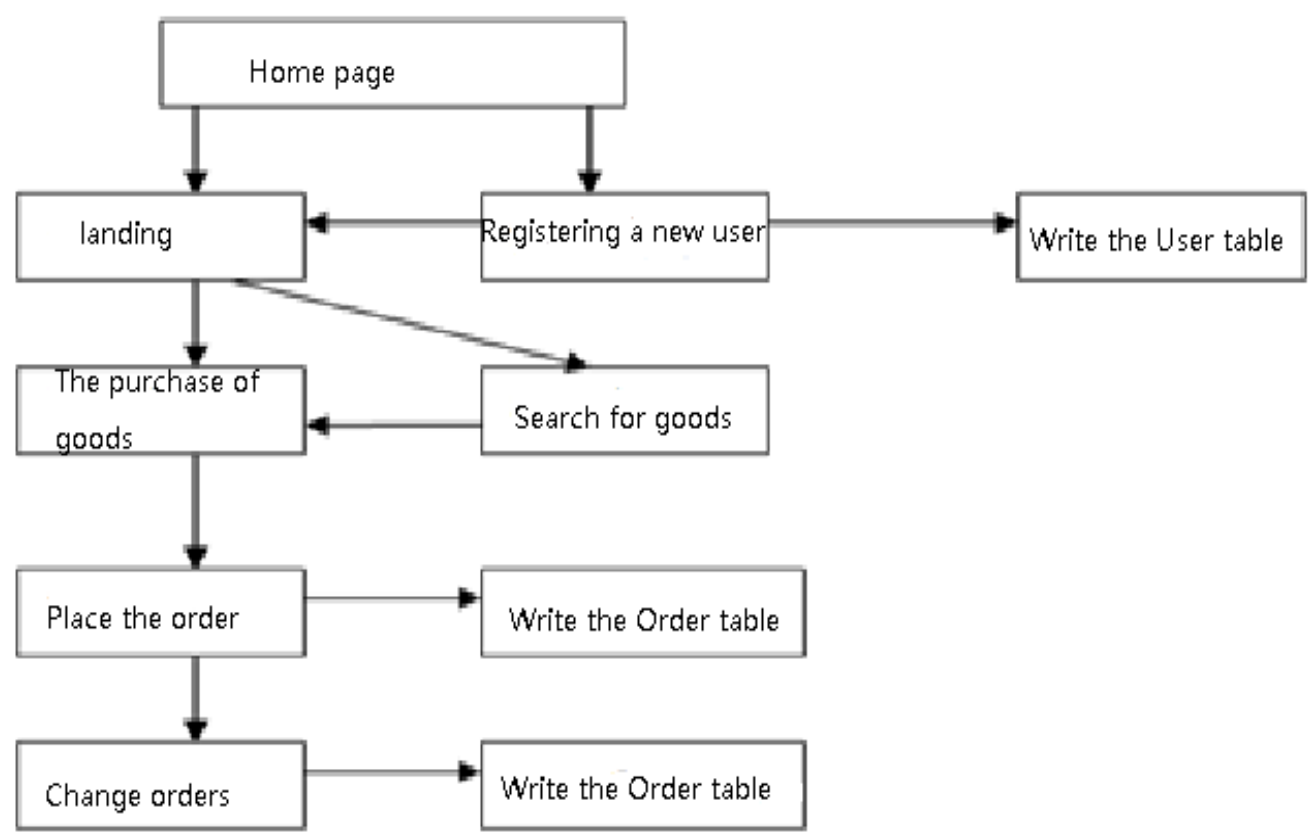

Fig. 2 The main module and data flow diagram

\section{The system test}

The purpose of the test. The purpose of testing is to determine more errors, in process, coding and layout, for example, may be some negligence, cause system instability or space error and so on.

The object of the test. This test is not only a program test. The definition and development of the test will run through the system of the whole cycle process. So, each time the resulting document, coding, and so should be the object of the test.

The results of the test. The user wants to buy this product, it is necessary to register as members of this site, and then to be allowed to log in, after login user can purchase items on this site.

Product classification: Administrators can add the category of goods and commodities in the background management.

Product search, can search Xpress users need the goods, search page in accordance with the classification of query, enter the user you want to search commodity, if the site, the result will be displayed directly and the details of the search to the goods listed. If you don't have the goods you want, there will be no goods you need to find. Or the search terms that the user itself entered is wrong, and there will be no product to be found.

Message board: Can message, the administrator can see.

Shopping cart: only login the user will have the right to use the shopping cart, when the user wants to order our website of a commodity, you can click the merchandise into the shopping cart, then the user can still modify the purchased quantity of a commodity or delete directly.

Submit orders: fill in the complete consignee information, will be specified before the next step operation.

Order query: Users can query their current or historical orders, enter the order number you want to find, you can query.

\section{Conclusions}

The rapid development of Internet technology, has become an integral part of people's daily life. A popular interactive online shopping system, a new shopping concept began to form and gradual development. People's life and work in the upcoming days, will be more and more dependent on 
advanced information technology, gradually, electronic, digital and networking virtualization. This design is to design a frame by ASP technology of dynamic online shopping system, so that people can easily shop at home.

\section{References}

[1] Jian Cao. ASP example tutorial [M]. Beijing: Electronic industry press, 2000.

[2] Yaodong Zheng, Qian Cai. ASP.NET Web database development instance extracts solution [M]. Beijing: tsinghua university press, 2006.1.

[3] Yichuan Yang, Mei Xu. ASP dynamic web page design of actual combat [M]. Beijing: mechanical industry publishing house, 2000.

[4] Youxian Xiao. The establishment of the theory of e-commerce credit guarantees mechanism. And the law of science and technology, 2003, (3): 23 and 24.

[5] Huai Zhou. The security of the ASP site analysis and prevention [J]. Beijing: the modern information technology, 2004. 